\title{
SUBSTITUTING SUCROSE USING STEVIOSIDE AND REBAUDIOSIDE A IN COOKIES AND HIBISCUS BEVERAGE
}

\author{
Mohamed, A. Hassan, Samir, I. Ghoneim ${ }^{1}$, M.A.S. Abdel-Samie ${ }^{1 *}$ and Ahmed A. Moursy ${ }^{1}$ \\ 1. Dept. Food and Dairy Sci. and Technol., Fac. Environ. Agric. Sci., Suez Canal Univ., Egypt
}

\begin{abstract}
The effect of substituting sucrose using some of stevia sweeteners (Stevioside and Rebaudioside A) at different substitution levels (50,75 and 100\%) on physical, chemical and sensory properties of cookies and hibiscus beverage was analyzed. In cookies samples; gradual replacement of sucrose by stevia sugars, decreased energy, total sugars (reducing and non-reducing sugars), breaking force, diameter and spread ratio of cookies while caused an increase in moisture, ash and thickness. In hibiscus beverage, the increase in stevia sweeteners decreased total soluble solids, acidity, total sugars, while increased $\mathrm{pH}$ values, and antioxidant activity. Sensory evaluation test showed that, rebaudioside A showed more acceptability than stevioside in both cookies and hibiscus beverage samples.
\end{abstract}

Key words: Stevioside, Rebaudioside A, cookies, hibiscus beverage.

\section{INTRODUCTION}

Stevia rebaudiana (Bertoni) is a perennial shrub of the Asteraceae (Compositae) family, native to South America (Ohta et al., 2010). The leaves naturally contain diterpene glycosides Stevioside and Rebaudiosides A, which are responsible for its sweet taste and have commercial value allover the world as sugar substitute in foods, beverage or medicines uses (Gupta et al., 2013).

Stevia sweeteners showed to be nontoxic and possess antioxidant, antimicrobial, antifungal and anti-carcinogenic activity. Stevioside and Rebaudiosides A is likely to become a major source of high potency low calorie sweetener for growing natural cookies and beverage (Gupta et al., 2013). The food industry has focused for the last several years on the production of lowcalorie foods as a response to the continuing growth of public interest in these products. Cookies and other sweet baked goods contain large amounts of sugars and are usually avoided by dieters and diabetes (Drewnowski and Almiron, 2009).
Hibiscus sabdariffa L. is an herbaceous plant that belongs to the family Malvaceae (Cissé et al., 2011). It is an annual herb cultivated for its leaves, stem, seed and calices (Fasoyiro et al., 2005). $H$. sabdariffa calices has high antioxidant content related to the presence of anthocyanins with potent antioxidant activity (El Sherif et al., 2011).

The different parts of hibiscus are the seeds, leaves and calyces and these have been used for making refreshing beverage and as food preserves. Hibiscus beverage have been found to be rich in vitamin $\mathrm{C}$ and other antioxidants such as flavonoids and minerals (Fasoyiro et al., 2005).

The increase demand for hibiscus beverages due to its low prices, nutritional and medicinal properties is on the high side (Bamishaiye et al., 2011).

Cookie is chemically leavened product, also known as biscuit. It is ideal for nutrient availability, palatability, compactness and convenience and differs from other baked products like bread and cakes because of having low moisture content, comparatively

\footnotetext{
* Corresponding author: Tel.: +201111138765

E-mail address: mampowerd@hotmail.com
} 
free from microbial spoilage and long shelf life of the product (Sharif et al., 2009).

This study aimed to produce low calorie cookies and hibiscus beverage while maintaining the sweet taste of sucrose by using Stevioside or Rebaudioside $\mathrm{A}$ as sugar substitutions. We also aimed to analyze the effects of those two sugar alternative on the quality of the prepared cookies and hibiscus beverage.

\section{MATERIALS AND METHODS}

Wheat flour ( $72 \%$ extraction), sugar, shortening, salt and baking soda used to produce cookies in this study, were purchased from local market. Stevioside and Rebaudioside A obtained from ElRebat Company for Distribution and Trade, Mansoura city, Egypt. Analytical grade chemicals and reagents were purchased from Al-Gomhuria Company, Ismailia, Egypt.

\section{Cookies and Hibiscus Beverage Preparation}

Cookies were prepared according to the method and formula of AACC (2002). Control formula of cookies was $225 \mathrm{~g}$ flour, shortening 64g, sugar $130 \mathrm{~g}$, salt $2.1 \mathrm{~g}$, baking powder $2.5 \mathrm{~g}$ and water $49 \mathrm{~g}$ Hibiscus beverage was prepared according to the method and formula of AOAC (2005).

The Dried hibiscus sepals $(30 \mathrm{~g})$ were soaked in tab water $(840 \mathrm{ml})$ at room temperature $25^{\circ} \mathrm{C}$ for 12 hours then, mixed with other contents including sweeteners (130 g sucrose or equal to the sweetness of this amount of sugar). Mixture was well mixed for two minutes and bottled in 250 $\mathrm{ml}$ glass bottles, heated to $90^{\circ} \mathrm{C}$ for another two minutes. Prepared bottles was cooled down by using tab water $25^{\circ} \mathrm{C}$ and stored at room temperature until analyses.

\section{Physical Properties}

Cookies spread ratio was measured according to the AACC method (2002)
After 30 minutes of removing the cookies from oven, six cookies were measured for diameter and thickness and divided by 6 to get the mean diameter and thickness of a single cookie sample. Spread ratio was calculated according to the following formula:

Spread ratio $(\mathrm{SR})=($ Diameter $\mathrm{D} /$ Thickness $\mathrm{T})$

Moisture of cookie samples was determined according to the method described by Askar and Treptow (1993). Ash contents of cookies were determined according to the Approved Methods (AACC, 2002). Gross energy of a substance is the amount of heat measured in calories that is released when the substance is completely oxidized in a bomb calorimeter. Caloric value of the cookie samples was determined using oxygen bomb calorimeter (Werke IKA C2000) according to Krishna and Ranjhan (1981).

Breaking force of cookies was measured 30 min after removing the cookies from the oven. A three-point bend test was made on six cookies using a texture analyzer (TATX2, Stable Microsystem, Surrey, England) equipped with a $25-\mathrm{kg}$ load cell.

The peak breaking force $(\mathrm{g})$ of cookies using the force-in-compression was recorded.

Cookie samples were placed on base beams with a distance of $4 \mathrm{~cm}$ between the two beams. A three-point bending rig was used with an HDP/BS, knife-edge probe. The analyzer was set at a return-to-start cycle, with a pretest speed of $2 \mathrm{~mm} / \mathrm{sec}$, test speed of $2 \mathrm{~mm} / \mathrm{sec}$, posttest speed of 10 $\mathrm{mm} / \mathrm{sec}$, the trigger force was $20 \mathrm{~g}$, and distance was $20 \mathrm{~mm}$ Abdel-Samie et al., (2010).

\section{Chemical Analyses}

Total soluble solids of hibiscus beverage was determined by using refractometer following the method described by Askar and Treptow (1993). Total sugars, reducing sugars and non-reducing sugars 
SINAI Journal of Applied Sciences (ISSN: 2314-6079), Vol. (5), Is. (1), Apr. 2016

Table (1): Treatments of sucrose substituting.

\begin{tabular}{cccc}
\hline Treatment & Sucrose (\%) & Stevioside (\%) & Rebaudioside A (\%) \\
\hline $\mathbf{T r}_{\mathbf{1}}$ & 100 & - & - \\
$\mathbf{T r}_{\mathbf{2}}$ & 50 & 50 & - \\
$\mathbf{T r}_{3}$ & 25 & 75 & - \\
$\mathbf{T r}_{4}$ & 50 & - & 50 \\
$\mathbf{T r}_{\mathbf{5}}$ & 25 & - & 75 \\
$\mathbf{T r}_{\mathbf{6}}$ & - & 50 & 50 \\
\hline
\end{tabular}

were determined as described in the official method of AOAC (2005). It is the method of Lane and Eyenon. $\mathrm{pH}$ values were measured using the $\mathrm{pH}$-meter (orion, A420A) at room temperature (Askar and Treptow, 1993). The anti-oxidant activity of cookies was determined by 2, 2Diphenyl-1-picrylhydrazyl (DPPH) method according to Lee et al. (2003).

Acidity was determined according to the methods of AOAC (1984) it is expressed as the amount of free acid (mainly as anhydrous citric acid) in product $(\mathrm{g} / 100 \mathrm{ml}$ beverage). Two $\mathrm{ml}$ of beverage was taken into $100 \mathrm{ml}$ flask, $10 \mathrm{ml}$ water and 1 drop of ph. ph indicator were added into the flask, then the mixture titrated against $0.1 \mathrm{~N}$ $\mathrm{NaOH}$ quite rapidly unit near $\mathrm{pH} 6$, then alkaline was added slowly up to $\mathrm{pH} 7$. Titration was finished by adding 4 drops at time until $\mathrm{pH}$ 8.1. A $\mathrm{pH}$-meter or titrate was used until the indicator colour went (faint pink colour). Total acidity expressed as percent of citric acid in samples.

\section{RESULTS AND DISCUSSION}

\section{Effect of Sugar Substitution Cookies Quality Characteristics}

Moisture

Effects of sugar substitution on moisture contents of cookies were illustrated in Table (2). Significant differences were noted when control samples $\left(\operatorname{Tr}_{1}\right)$ were compared to sugar substituted samples. It was found that maximum moisture content was that of (Tr6) cookie samples $(6.99 \%)$ which used Stevioside and Rebaudioside A (50:50) instead of sucrose. Minimal moisture was observed in control sample $\left(\operatorname{Tr}_{1}\right)$ which has sucrose as the only sweetener.

Moisture contents increased significantly with the decrease of sucrose from $3.96 \%$ in control sample to $4.89,5.2,4.79,5.2$ and 6.99, in $\operatorname{Tr}_{2}, \operatorname{Tr}_{3}, \mathrm{Tr}_{4}, \mathrm{Tr}_{5}$, and $\operatorname{Tr}_{6}$ respectively. The increase in moisture content of cookies samples with the replacement of sucrose was combined with comparatively lower volume these changes may be due to the increase in flour weight to whole weight which caused higher water absorption.

These findings were in accordance with Galal (1998) who reported an increase of moisture contents of cookies with the decrease in sucrose.

\section{Energy}

Clear significant differences in energy values were observed (Table 2), control cookies $\left(\operatorname{Tr}_{1}\right)$ contained $377.1 \mathrm{cal} / 100 \mathrm{~g}$, while substitution of $50 \%$ of sugar decreased the energy contents to 318.1 and $311.8 \mathrm{cal} / 100 \mathrm{~g}$ in $\left(\mathrm{Tr}_{2}\right)$ and $\left(\mathrm{Tr}_{4}\right)$, respectively. When $75 \%$ Steviosude and Rebaudioside A has been used, the total energy contents were 286.4 and 285.8 in $\left(\operatorname{Tr}_{3}\right)$ and $\left(\operatorname{Tr}_{5}\right)$, respectively. 
The lowest energy value was that of $\left(\operatorname{Tr}_{6}\right)$ with the energy value of $259.3 \mathrm{cal} / 100$ $\mathrm{g}$, The lower energy values in the reduced sucrose treatments was because of the removal of sucrose which is the biggest source of calories among cookies formula. These findings are in agreement with the results obtained by Mahamoud et al., (2002) who reported that energy values decreased with the replacement of sucrose with other intense non-calorific sweeteners.

\section{Sugars}

Stevioside and Rebaudioside A are both non-carbohydrate materials, thus substitution of $50 \%$ of sugar decreased total sugars from $20 \%$ in control cookies $\left(\operatorname{Tr}_{1}\right)$ to $15 \%$ for both $\left(\operatorname{Tr}_{2}\right)$ and $\left(\operatorname{Tr}_{4}\right)$.

Further decrease in total sugars was noted with the $75 \%$ of sugars substitution at $\left(\mathrm{Tr}_{3}\right)$ and $\left(\mathrm{Tr}_{5}\right)$ with total sugar contents of $12 \%$ for each. Minimum total sugar contents $(4.0 \%)$ was noted in $\left(\operatorname{Tr}_{6}\right)$ where no sucrose was added to the formula.

These results were in agreement with the results of (Askar and Treptow, 1985), who reported that total sugars were decreased when sucrose has proportionally removed from cookies formula. The use of Stevioside and Rebaudioside A instead of sucrose in cookies led to a decrease in reducing sugars. When Stevioside or Rebaudioside A was used as a substitution instead of $50 \%$ of sugars, reducing sugars were decreased from 8 in control cookies $\left(\operatorname{Tr}_{1}\right)$ to $4 \%$ for both $\left(\operatorname{Tr}_{2}\right)$ and $\left(\operatorname{Tr}_{4}\right)$. Further decrease in reducing sugars was noted in the $75 \%$ of sugars substitution at $\left(\mathrm{Tr}_{3}\right)$ and $\left(\operatorname{Tr}_{5}\right)$ with a reducing sugars contents of $3 \%$ in both treatments. Minimum reducing sugars contents was noted in $\left(\operatorname{Tr}_{6}\right)$ (with no sucrose added).

Removing sucrose from formula led to the decrease of non-reducing sugars. In $50 \%$ of sugar substitution, non-reducing sugars decreased from $12 \%$ in control cookies $\left(\operatorname{Tr}_{1}\right)$ to $11 \%$ in both $\left(\operatorname{Tr}_{2}\right)$ and
$\left(\operatorname{Tr}_{4}\right)$. Further decrease in non-reducing sugars was noted with the $75 \%$ of sugars substitution at $\left(\operatorname{Tr}_{3}\right)$ and $\left(\operatorname{Tr}_{5}\right)$ with a contents of $9 \%$ for each.

The minimum non-reducing sugar content $(3 \%)$ was noted in $\left(\operatorname{Tr}_{6}\right)$. This trend was in agreement with the results obtained by Askar and Treptow (1985) whose results showed that substituting sucrose for alternative sweeteners reduced nonreducing sugars in cookies.

\section{Ash Contents}

Control treatment $\left(\operatorname{Tr}_{1}\right)$ contained $0.56 \%$ of ash contents, while in 50\% sugar substitution showed an increase in ash contents $(0.75 \%$ and $0.85 \%)$ was noticed in $\left(\mathrm{Tr}_{2}\right)$ and $\left(\mathrm{Tr}_{4}\right)$ in Stevioside and Rebaudiosid A added cookies respectively. The $75 \%$ sugar substitution showed further increase in ash content (1.02 and 1.03) for $\left(\mathrm{Tr}_{3}\right)$ and $\left(\mathrm{Tr}_{5}\right)$, respectively. Maximum ash contents $(1.56 \%)$ was that of the $100 \%$ sugar substitution using 50\% Stevioside and $50 \%$ Rebaudioside A. These findings are in line with the results obtained by El-Azab and Bothayna (1997) who reported that alternative sweeteners led to an increase in ash contents due to the removal of sucrose which is very poor in minerals and increase of flour ratio which is higher in ash content.

\section{Breaking Force}

One of the important roles of sugar in cookies is the adsorption of water in a competition with the flour, so as to build the gluten network. Thus, removing of sucrose, as the hygroscopic material which carry water on its surfaces disturb the structure and will surely reduce breaking forces, as could be seen in Table (2).

Control treatment $\left(\operatorname{Tr}_{1}\right)$ had the maximum breaking force with an average of $5.51 \mathrm{~kg}$, while the application of Stevioside and Rebaudioside A in the 50\% substituted cookies decreased the breaking force to $4.31 \mathrm{~kg}$, and $4.30 \mathrm{~kg}$ in $\mathrm{Tr}_{2}$ and $\mathrm{Tr}_{4}$, respectively. The minimum breaking 
SINAI Journal of Applied Sciences (ISSN: 2314-6079), Vol. (5), Is. (1), Apr. 2016

Table (2): Effect of sugar substitution on cookies quality characteristics.

\begin{tabular}{|c|c|c|c|c|c|c|c|c|c|c|}
\hline \multirow[t]{2}{*}{ "Treatment } & \multirow{2}{*}{$\begin{array}{c}\text { Moisture } \\
\text { (\%) }\end{array}$} & \multirow{2}{*}{$\begin{array}{l}\text { Energy } \\
\text { cal/100g }\end{array}$} & \multicolumn{3}{|c|}{ Sugars (\%) } & \multirow{2}{*}{$\begin{array}{l}\text { Ash } \\
\text { (\%) }\end{array}$} & \multirow{2}{*}{$\begin{array}{l}\text { Breaking } \\
\text { force }(\mathbf{k g})\end{array}$} & \multicolumn{3}{|c|}{ Spread } \\
\hline & & & Total & reducing & $\begin{array}{c}\text { Non } \\
\text { reducing }\end{array}$ & & & $\begin{array}{c}\text { Diameters } \\
(\mathrm{cm})\end{array}$ & $\begin{array}{c}\text { Thickness } \\
(\mathrm{cm})\end{array}$ & $\begin{array}{c}\begin{array}{c}\text { Spread } \\
\text { ratio }\end{array} \\
\end{array}$ \\
\hline$T \mathbf{T r}_{1}$ & $* 3.96^{\mathrm{d}}$ & $377.1^{\mathrm{a}}$ & $20^{\mathrm{a}}$ & $8.0^{\mathrm{a}}$ & $12.0^{\mathrm{a}}$ & $0.56^{\mathrm{d}}$ & $5.51^{\mathrm{a}}$ & $6.45^{\mathrm{a}}$ & $1.00^{d}$ & $6.45^{\mathrm{a}}$ \\
\hline $\mathbf{T r}_{2}$ & $4.89^{\mathbf{c}}$ & $318.1^{\mathbf{b}}$ & $15^{\mathrm{b}}$ & $4.0^{\mathrm{b}}$ & $11.0^{\mathrm{b}}$ & $0.75^{\mathbf{c}}$ & $4.31^{\mathrm{b}}$ & $6.27^{\mathrm{b}}$ & $1.10^{\mathrm{c}}$ & $5.70^{\mathrm{b}}$ \\
\hline $\mathbf{T r}_{3}$ & $5.20^{\mathbf{b}}$ & $286.4^{\mathrm{c}}$ & $12^{\mathrm{c}}$ & $3.0^{\mathrm{b}}$ & $9.00^{\mathrm{c}}$ & $1.02^{\mathbf{b}}$ & $3.17^{\mathrm{c}}$ & $5.77^{\mathfrak{c}}$ & $1.20^{\mathrm{b}}$ & $4.81^{\mathrm{c}}$ \\
\hline $\operatorname{Tr}_{4}$ & $4.79^{\mathrm{c}}$ & $311.8^{\mathbf{b}}$ & $15^{\mathbf{b}}$ & $4.0^{\mathbf{b}}$ & $11.0^{\mathrm{b}}$ & $0.85^{\mathbf{c}}$ & $4.30^{\mathbf{b}}$ & $6.05^{\mathbf{b}}$ & $1.10^{\mathrm{c}}$ & $5.50^{\mathrm{b}}$ \\
\hline $\operatorname{Tr}_{5}$ & $5.20^{\mathrm{b}}$ & $285.8^{\mathrm{c}}$ & $12^{\mathrm{c}}$ & $3.0^{\mathrm{b}}$ & $9.00^{\mathbf{c}}$ & $1.03^{\mathrm{b}}$ & $3.14^{\mathrm{c}}$ & $5.74^{\mathrm{c}}$ & $1.20^{\mathrm{b}}$ & $4.79^{\mathrm{c}}$ \\
\hline $\operatorname{Tr}_{6}$ & $6.99^{\mathrm{a}}$ & $259.3^{d}$ & $4.0^{\mathrm{d}}$ & $1.0^{\mathrm{c}}$ & $3.00^{\mathrm{d}}$ & $1.56^{\mathrm{a}}$ & $2.88^{\mathrm{d}}$ & $5.08^{d}$ & $1.40^{\mathrm{a}}$ & $3.88^{\mathrm{d}}$ \\
\hline
\end{tabular}

force was noted in the non - added sucrose treatment $\left(\operatorname{tr}_{6}\right)$ with a score of $2.88 \mathrm{~kg}$. Those findings were in line with those mentioned by Mahamoud et al. (2002) who reported a decrease in breaking forces of cookies with application of alternative sweeteners in cookies formulation.

\section{Spread of Cookies}

Cookies spread are a ratio between diameter and thickness. As a result of a decreased diameter and relatively increased thickness, cookies spread ratios decreased with the sugar substitution. Spread ratio of the control samples $\operatorname{Tr}_{1}$ was $6.45 \mathrm{~cm}$ and it was the maximum spread value.

Application of Stevioside and Rebaudioside A decreased the spread ratio to 5.70 and 5.50 in the $50 \%$ replacement of sugar in $\mathrm{Tr}_{2}$ and $\mathrm{Tr}_{4}$, respectively. Cookies spread decreased to 4.81 and 4.79 in the $75 \%$ substituted sugar cookies. Same trends were noted with $\operatorname{Tr}_{6}$ with a minimum spread ration compare to all other treatments, with a spread score of 3.88. The decreased spread ratio when sugar was substituted using alternative sweeteners including Stevioside and Rebaudioside A might be due to the harder gluten network formed with the absence of sucrose which play a role in a loose texture by adsorbing water on its surface and to reduce water available used for the gluten network to develop. That comes in line with results of Peck (1994).

\section{Effect of Sugar Substitution on Hibiscus Beverage Quality Characteristics}

\section{Total Soluble Solids (TSS)}

Table (3) shows the changes in T.S.S percentage in hibiscus beverage due to the effect of sugar substitution. Significant decrease was noted when control samples were compared to sugar substituted hibiscus beverage samples. The maximum T.S.S content (14.8) was recorded in $\left(\operatorname{Tr}_{1}\right)$ which contain $100 \%$ sucrose. While the minimum content was recorded in $\left(\operatorname{Tr}_{6}\right)$ where sugar was substituted with Stevioside and Rebaudioside A (50:50). $\mathrm{Tr}_{2}, \mathrm{Tr}_{3}, \mathrm{Tr}_{4}$ and $\mathrm{Tr}_{5}$ contained T.S.S of $10.3,8.1,9.0$ and 8.4 , respectively which were all lower than T.S.S in control sample Tr1. This observation was in agreement with the results obtained by El-Zoghbi and Siliha, (1992) who reported that T.S.S decreased when sucrose was removed from apricot nectar.

\section{Total Acidity}

It was clear that added sweeteners decreased the acidity values of hibiscus beverage significantly. The highest acidity value was noted in control treatment $\operatorname{Tr}_{1}$ (0.96), while lowest value was recorded in $\operatorname{Tr}_{6}$ when Stevioside and Rebaudioside A were used instead of sucrose at ration 50:50. This decrease in acidity may be due to the absence of sucrose. These results are in agreement with the results of AbdelSamie (2007) who reported an increase in 
Table (3): Effect of sugar substitution on hibiscus beverage quality characteristics.

\begin{tabular}{cccccccc}
\hline Treatment & T.S.S & Acidity & $\mathbf{p H}$ & $\begin{array}{c}\text { Anti-oxidant } \\
\text { (\%) }\end{array}$ & \multicolumn{3}{c}{ Sugars (\%) } \\
\cline { 6 - 8 } & $(\%)$ & $(\%)$ & & & Total & Reducing Non Reducing \\
\hline $\mathbf{T r}_{\mathbf{1}}$ & $14.8^{\mathbf{a}}$ & $0.96^{\mathbf{a}}$ & $3.10^{\mathbf{d}}$ & $61.05^{\mathbf{d}}$ & $12.5^{\mathbf{a}}$ & $5.50^{\mathbf{a}}$ & $7.00^{\mathbf{a}}$ \\
$\mathbf{T r}_{\mathbf{2}}$ & $10.3^{\mathbf{b}}$ & $0.85^{\mathbf{b}}$ & $3.25^{\mathbf{c}}$ & $72.47^{\mathbf{c}}$ & $7.50^{\mathbf{b}}$ & $2.00^{\mathbf{b}}$ & $5.50^{\mathbf{b}}$ \\
$\mathbf{T r}_{3}$ & $8.10^{\mathbf{c}}$ & $0.81^{\mathbf{c}}$ & $3.42^{\mathbf{b}}$ & $76.19^{\mathbf{b}}$ & $6.00^{\mathbf{c}}$ & $1.50^{\mathbf{c}}$ & $4.50^{\mathbf{c}}$ \\
$\mathbf{T r}_{\mathbf{4}}$ & $9.00^{\mathbf{b}}$ & $0.87^{\mathbf{b}}$ & $3.28^{\mathbf{a}}$ & $74.83^{\mathbf{c}}$ & $7.50^{\mathbf{b}}$ & $2.00^{\mathbf{b}}$ & $5.50^{\mathbf{b}}$ \\
$\mathbf{T r}_{\mathbf{5}}$ & $8.40^{\mathbf{c}}$ & $0.82^{\mathbf{c}}$ & $3.41^{\mathbf{c}}$ & $77.61^{\mathbf{b}}$ & $6.00^{\mathbf{c}}$ & $1.50^{\mathbf{c}}$ & $4.50^{\mathbf{c}}$ \\
$\mathbf{T r}_{\mathbf{6}}$ & $6.30^{\mathbf{d}}$ & $0.65^{\mathbf{d}}$ & $3.81^{\mathbf{a}}$ & $78.12^{\mathbf{a}}$ & $4.00^{\mathbf{d}}$ & $1.00^{\mathbf{d}}$ & $3.00^{\mathbf{d}}$ \\
\hline
\end{tabular}

acidity values with storage of guava and mango sugar substituted beverages.

\section{pH Value}

$\mathrm{pH}$ values of hibiscus beverage are shown in Table 3. It is clear that addition of the sweeteners increased the $\mathrm{pH}$ values of hibiscus beverage. Control treatment $\left(\mathrm{Tr}_{1}\right)$ had the lower $\mathrm{pH}$ value (3.10), while the higher value (3.81) was recorded in Tr6 when Stevioside and Rebaudioside $\mathrm{A}$ in ratio 50:50 was used instead of sucrose.

Abdel-Samie (2007) reported that $\mathrm{pH}$ values increased when sucrose has been removed from guava beverage.

\section{Anti-oxidant Activity}

The use of Stevioside and Rebaudioside A instead of sucrose in formula led to the increase of antioxidant activity in all treatments compared to the control treatments with score of $61.05 \%$. The substitute of $50 \%$ of sugar increased the antioxidant activity to 72.47 and $74.83 \%$ in $\mathrm{Tr}_{2}$ and $\mathrm{Tr}_{4}$, respectively. The higher values of antioxidant (78.12) were obtained when sucrose removed completely in $\operatorname{Tr}_{6}$. These results are in agreement with the results of Delva et al. (2005) who reported that antioxidant value increased when sucrose was substituted using stevia sweeteners.

\section{Total Sugars}

Table 3 presents the sugars concentrations (total, reducing and nonreducing sugars) in beverage, respectively. Stevioside and Rebaudioside A are both non-carbohydrate materials thus substitution of $50 \%$ of sugar decreased total sugars from $12.5 \%$ in control cookies $\left(\operatorname{Tr}_{1}\right)$ to $7.5 \%$ and $7.5 \%$ in $\left(\mathrm{Tr}_{2}\right)$ and $\left(\mathrm{Tr}_{4}\right)$, respectively. Further decrease in total sugars was noted with the $75 \%$ of sugars substitution in $\left(\operatorname{Tr}_{3}\right)$ and $\left(\operatorname{Tr}_{5}\right)$ with a contents of 6.0 and 6.0 , respectively. The minimum total sugar content was noted in $\left(\operatorname{Tr}_{6}\right)$ without sucrose. This result was in agreement with the results obtained by Abdel-Samie (2007).

On the other hand, minimum reducing sugars was recorded in $\operatorname{Tr}_{6}$ when no sucrose was added to hibiscus beverage. While maximum reducing sugars $\left(\operatorname{Tr}_{1}\right)(5.5 \%)$ was that of control hibiscus beverage.

On contrary, control sample $\operatorname{Tr}_{1}$ had that maximum content $(7 \%)$ of non-reducing sugars, while sugar substituted hibiscus beverage had less non-reducing sugar content of $5.5,4.5 \%$ in Stevioside containing hibiscus beverage and 5.5 and $4.5 \%$ in Rebaudioside A containing hibiscus beverage. 


\section{Sensory Evaluation Test}

\section{Sensory Evaluation of Cookies}

Fig. 1 shows appearance, texture, flavortaste and overall acceptability of cookies.

\section{Appearance}

There were significant differences between treatments. The best appearance was scored in $\operatorname{Tr}_{1}, \operatorname{Tr}_{2}$ and $\operatorname{Tr}_{5}$. Samples with Stevioside at of $50 \%$ sucrose substitution and Rebaudioside A instead of $75 \%$ sucrose recorded the best appearance. But when Stevioside used at substitution level $75 \%\left(\mathrm{Tr}_{3}\right)$ recorded lower appearance score. Rebaudioside A as 50\% sugar substitution $\left(\mathrm{Tr}_{4}\right)$ and Stevioside with Rebaudioside A 50:50 recorded the lowest score of appearance. Less colour score for $\mathrm{Tr}_{2}, \mathrm{Tr}_{3}, \mathrm{Tr}_{4}, \mathrm{Tr}_{5}$ and $\operatorname{Tr}_{6}$ was due to the absence of brown colour of Millared reaction with the absence of sucrose.

\section{Texture}

The best texture was recorded with $\operatorname{Tr}_{5}$ when Rebaudioside A used as 75\% sugar substitution. The lowest texture score was recorded with $\operatorname{Tr}_{6}$ when Stevioside with Rebaudioside A used in ratio 50:50 without sucrose addition. Less scores of texture of sugar substituted cookies might be related to the higher moisture contents.

\section{Flavor and Taste}

There were significant differences between treatments. The best flavor and taste was scored in $\operatorname{Tr}_{5}$ that used Rebaudioside A instead of $75 \%$ sucrose, while the worst flavor and taste scored in Tr6 with no sucrose added. It is clear that $\operatorname{Tr}_{1}, \mathrm{Tr}_{3}, \mathrm{Tr}_{4}$ recorded the same lower score. Decreased flavor in Stevioside added cookies may be because the after taste effect of Stevioside.

\section{Overall Acceptability}

There were significant differences between treatments. The highest score was achieved with $\operatorname{Tr}_{1}, \operatorname{Tr}_{2}$ and $\operatorname{Tr}_{5}$ with excellent acceptability.

It is clear that treatments which use stevioside instead of $75 \%$ sucrose and Rebaudioside A instead of $50 \%$ sucrose recorded lower score. But when Stevioside with Sebaudioside A 50:50 recorded lowest score of overall acceptability.

As a matter of fact overall acceptability a measure of liking to panelists which may be an average of all previously mentioned sensory parameters, so overall acceptability of sugar substituted prepared products were lower than control.

\section{Sensory Evaluation of Hibiscus Beverage}

Fig. (2) sensory evaluation of hibiscus beverage showed that control sample $\operatorname{Tr}_{1}$ was better than sugar substituted samples. Color score of control hibiscus beverage was 8 while other treatments $\operatorname{Tr}_{2}, \mathrm{Tr}_{3}, \mathrm{Tr}_{4}$, $\operatorname{Tr}_{5}$ and $\operatorname{Tr}_{6}$ ranged from 7-8. Odor had no differences between treatments.

Flavor scores decreased gradually with the application of $\mathrm{Tr}_{2}, \mathrm{Tr}_{3}, \mathrm{Tr}_{4}, \mathrm{Tr}_{5}$ and $\mathrm{Tr}_{6}$. Overall acceptability, control samples got a score of 8 without differences with $\mathrm{Tr}_{2}, \mathrm{Tr}_{3}$ and with differences with $\operatorname{Tr}_{4}, \operatorname{Tr}_{5}$ and $\operatorname{Tr}_{6}$ which ranged in 6-7 scores. Less sensory scores might be due to the desired taste profile of sucrose loved by consumers and also because of the after taste of the stevioside.

\section{Colour}

The best colour was scored with $\mathrm{Tr}_{2}, \mathrm{Tr}_{3}$, $\operatorname{Tr}_{4}$ and $\operatorname{Tr}_{5}$. It was found that treatments which use Stevioside with Rebaudioside A 50:50 recorded lower colour score.

\section{Odor}

There were significant difference in $\operatorname{Tr}_{6}$ when Stevioside with Reabudioside A were a sugar substitution 50:50 scored a lowest odor score compared with all other treatments $\mathrm{T}_{1}, \mathrm{~T}_{2}, \mathrm{Tr}_{3}, \mathrm{Tr}_{4}$ and $\mathrm{Tr}_{5}$ were get the same score. 


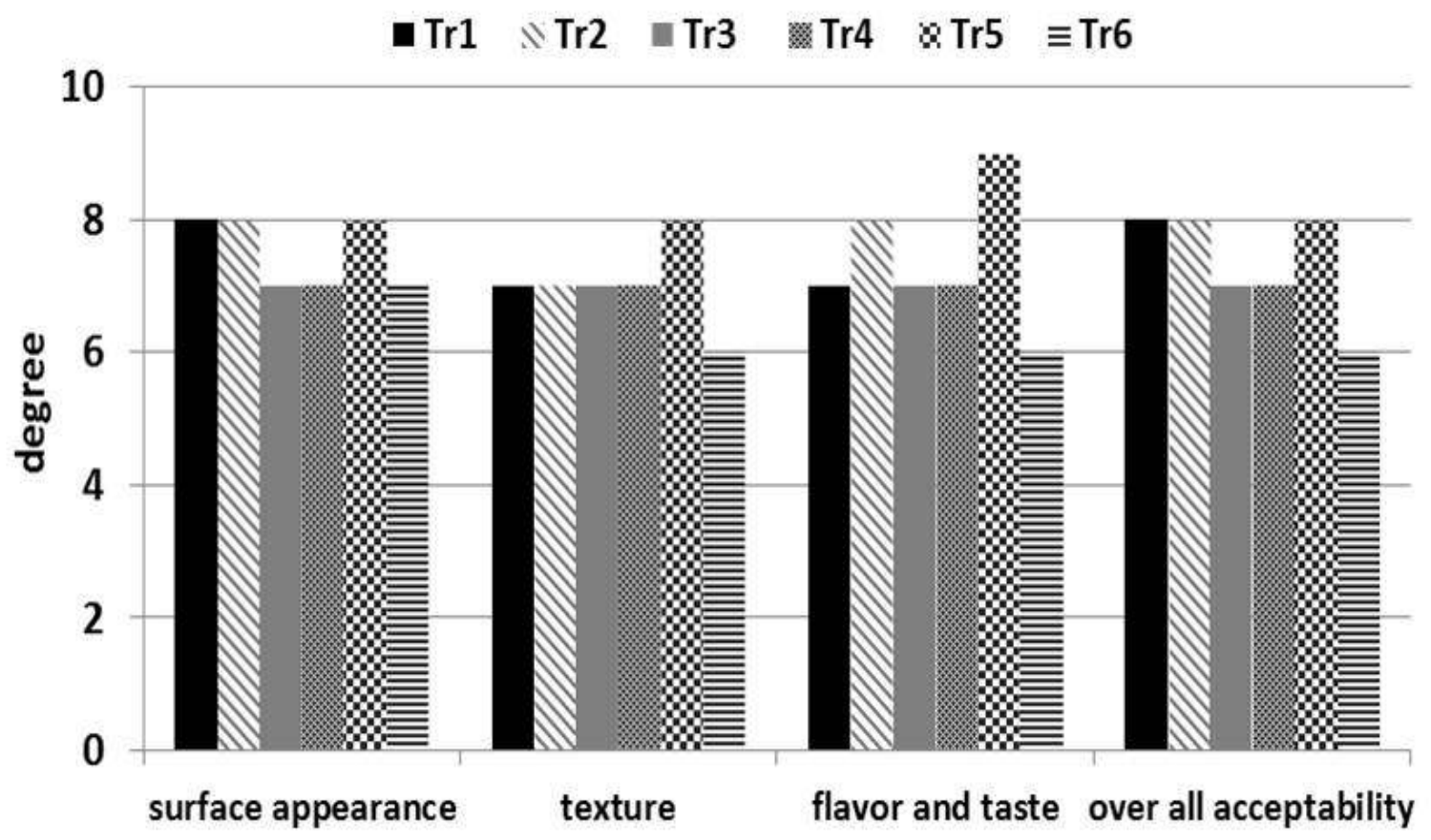

Fig. (1): Effects of sugar replacement on sensory evaluation of cookies.

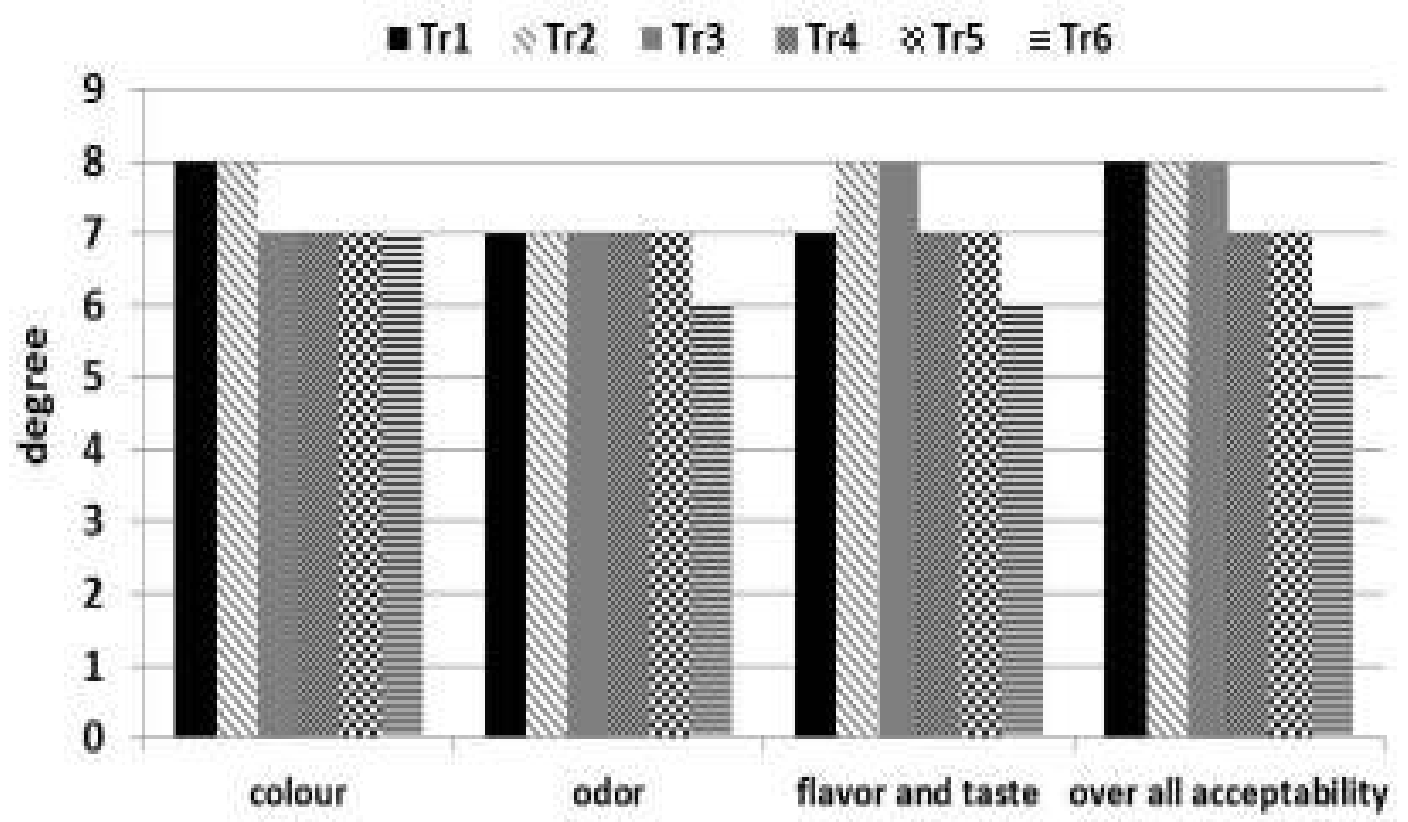

Fig. (2): effects of sugar replacement on sensory evaluation of hibiscus beverage. 


\section{Flavor and taste}

The best flavor and taste was recorded with $\operatorname{Tr}_{2}$ and $\operatorname{Tr}_{3}$ that used Stevioside and rebaudioside A instead of $50 \%$ sucrose, while worst flavor and taste scored in $\operatorname{Tr}_{6}$ with no sucrose added. it is clear that $\operatorname{Tr}_{1}, \operatorname{Tr}_{4}, \operatorname{Tr}_{5}$ recorded same lower score.

\section{Overall acceptability}

The best score in overall acceptability was scored in control treatment $\operatorname{Tr}_{2}$ and $\operatorname{Tr}_{3}$ that used Stevioside and Rebaudioside A instead of $50 \%$ sucrose, while the lowest overall acceptability was observed in Tr6 with any sucrose added.

\section{CONCLUSION}

It can be concluded that both Stevioside and Rebaudioside A can be used instead of sucrose to produce low-calorie cookies and beverage; it is safer, economical and has no bad effects on the chemical and physical properties of the prepared cookies and hibiscus beverage.

\section{REFERENCE}

AACC (2002). Approved Methods of Analysis, Methods 10-50D, 44-15 and 46-12. AACC International: St. Paul, $\mathrm{MN}$.

Abdel-Samie, M.A.S. (2007). MSc. Thesis, Faculty of environmental agriculture since, Suez Canal University . Egypt

Abdel-Samie, M.A.S.; Wan, W.; Huang, J.; Chung, O.K. and Xu, B. (2010). Effects of cumin and ginger as antioxidants on dough mixing properties and cookie quality. Cereal Chem. J., 87 (5): 454-460

AOAC (1984). Official Methods of Analysis. Association of Official Analytical Chemist's. Editor: Williams S.Arlington, Virginia, USA.

AOAC (2005). Official Methods of Analysis of the Association of Official
Analytical Chemists, $18^{\text {th }}$ Ed., AOAC International, Arlington, Virginia, USA.

Askar, A. and Treptow, H. (1985). Fructose as sugar substitute: properties, metabolism and uses. In: Ernahrungsumschau, 32: 135.

Askar, A. and Treptow, H. (1993). Analytical methods In: Quality Assurance in Tropical Fruits Processing (book).

Bamishaiye, E.I.; Olayemi, F.F. and Bamishaiye, O.M. (2011). Effects of boiling time on mineral and vitamin $\mathrm{C}$ content of three varieties of Hibiscus sabdriffa beverage in Nigeria. World Journal of Agri. Sc., 7(1): 62-67.

Cisse, M.F.; Vaillant, D.; Reynes, M.S.; and Dornier, M. (2011). Crossflow microfiltration for the cold stabilization of roselle (Hibiscus sabdariffa L.) extract. J Food Eng., 106 (1): 20-27.

Drewnowski, A. and Almiron, R.E. (2009). Human Perceptions and Preferences for Fat-Rich Foods. Fat Detection: Taste, Texture, and Post Infective Effects, 265.

Delva, J.; Smith, M.P.; Howell, R.L.; Harrison, D.F.; Wilke, D. and Jackson D.L. (2005). A study of the relationship between protective behaviors and beverageing consequences among undergraduate college students. J. Ame. College Health, 53: 19-26

El-Azab, M.A. and Bothayna, M. (1997). Production of cake contaning bran, sweeteners substitutes and bulking agents. Arab. Univ. J. Agri. Sc., Ain Shams Univ., Cairo, 5 (2): 275-296.

El Sherif, F.; Khattab, S.; Goniam, E.; Salem, N. and Radwan, K. (2011). Effect of gamma irradiation on enhancement of some economic traits and molecular changes in Hibiscus Sabdariffa. Life Sc. J., 8 (3): 220-229. 
El-Zoghbi, M. and Siliha, H. (1992). The effect of low-calorie sweetener on chemical and physical properties of apricot nectar. In: Alimenta, Quality Control, 19-21

Fasoyiro, S.B; Babalola, S.O. and Owosibo, T. (2005). Chemical composition and sensory quality of fruit-flavoured roselle (Hibiscus sabdariffa) beverage.

Galal, W.F. (1998). Quality characteristics of macaroni as affected by addition of some by-products rich in fiber. M.Sc. Thesis. Fac. Agri., Cairo Univ. Egypt, 51- 54.

Gupta, E.; Purwar, S.; Sundaram, S. and Rai, G.K. (2013). Nutritional and therapeutic values of Stevia rebaudiana: A review. J. Medicinal Plants Res., 7 (46): 3343-3353.

Krishna, G. and Ranjhan, S.K. (1981). Laboratory Manual for Nutrient Research. $1^{\text {st }}$ Ed, Vikas Publishing House Pvt Ltd New Delhi, India.
Lee, S.E.; Hwang, H.J. and Ha, J.S. (2003). Screening of medicinal plant extracts for antioxidant activity, Life Science, 73: 167-179.

Mahamoud, R.M.; El-Shatanovi, G.A.A.; Asad, E.A.M. and Abdel-Khalek, M.H. (2002). Using of dietary fiber and sugarfat substitution in the production of low calorie cakes. Res. Bult., Ain Shams Univ., 1: 1-16

Ohta, M.; Sasa, S.; Inoue, A.; Tamai, T.; Fujita, I.; Morita, K. and Matsuura, F.J. (2010). Appl Glyco Sc., 57: 199209.

Peck, A. (1994). Intense sweeteners for bakery products. Technical Bulletin, American Institute of Baking Research Department, 16 (2): 1- 8.

Sharif, M.K.; Butt, M.S.; Anjum, F.M.; and Nawaz, H. (2009). Preparation of fiber and mineral enriched defatted rice bran supplemented cookies. Pak. J. Nutr., 8: 571-577. 
SINAI Journal of Applied Sciences (ISSN: 2314-6079), Vol. (5), Is. (1), Apr. 2016

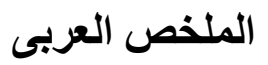

استبدال السكروز بالاستيفوسيد و الريبيديوسيد A في المخبوزات ومشروب الكـركــيه

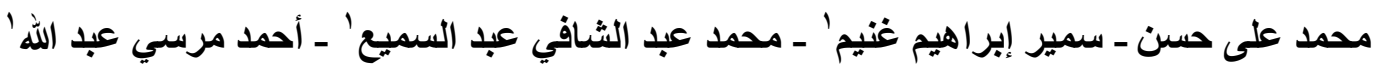

ا ـ قسم علوم وتكنولوجيا الأغذية، كلية العلوم الزر اعية البيئية بالعريش، جامعة قناة السويس، مصر

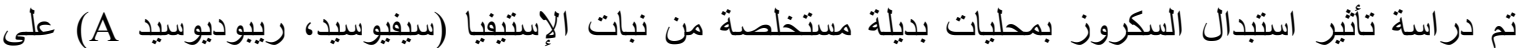

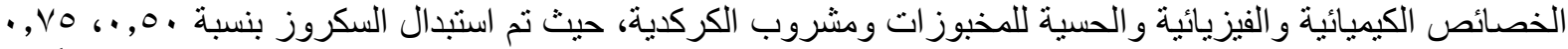

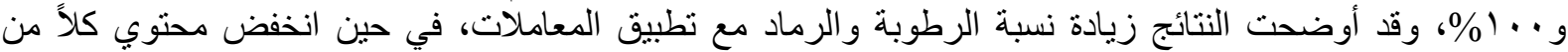

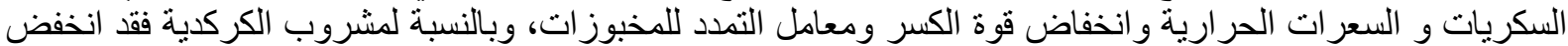

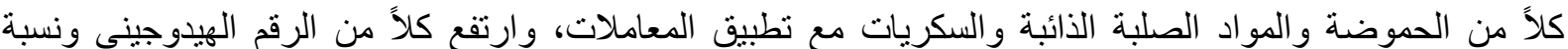

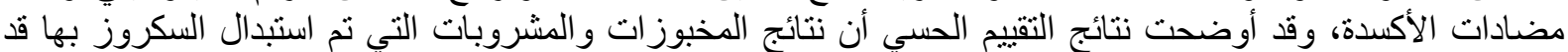

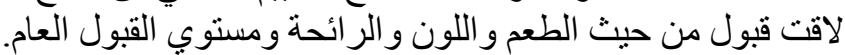
الكلمات الإسترشادية: السكروز، الإستنفوسيد، الريبيديوسيد A، مشروب ونيد الكركدية، الرخبوزات. 
